\title{
MicroRNAs in asthma pathogenesis - from mouse to man
}

\author{
Julie Weidner, Carina Malmhäll, Madeleine Rådinger \\ Krefting Research Centre, Department of Internal Medicine and Clinical Nutrition, Institute of Medicine, University of Gothenburg, \\ Gothenburg SE-40530, Sweden.
}

Correspondence to: Dr. Madeleine Rådinger, Krefting Research Centre, Department of Internal Medicine and Clinical Nutrition, Institute of Medicine, University of Gothenburg, Box424, Gothenburg SE-40530, Sweden. E-mail: madeleine.radinger@gu.se

\begin{abstract}
How to cite this article: Weidner J, Malmhäll C, Rådinger M. microRNAs in asthma pathogenesis - from mouse to man. J Trans/ Genet Genom 2019;3:2. https://doi.org/10.20517/jtgg.2018.30
\end{abstract}

Received: 1 Oct 2018 First Decision: 7 Nov 2018 Revised: 27 Nov 2018 Accepted: 3 Dec 2018 Published: 20 Jan 2019

Science Editor: Faoud Terrence Ishmael Copy Editor: Cui Yu Production Editor: Huan-Liang Wu

\begin{abstract}
Asthma is a heterogenic disease affecting over 300 million people of all ages and socioeconomic status worldwide. The disease is characterized by chronic airway inflammation, reversible airflow obstruction, wheeze, cough and shortness of breath. Although asthma has been traditionally described by phenotypes such as immune cell type or allergy, it is clear that a variety of subtypes have emerged, adding further complexity to the disease. microRNAs are small, non-coding RNAs that act as regulatory molecules, binding to one or several target mRNAs, often resulting in translational silencing. In recent years, microRNAs have been the subject of many studies in order to better understand the mechanisms driving asthma development as well as discovery of potential biomarkers for asthma. In this review, we focus on the emerging role of microRNAs in asthma, from animal models to human cohorts.
\end{abstract}

Keywords: microRNA, asthma, allergy, animal models, human, endotype, biomarker, phenotype

\section{INTRODUCTION}

Asthma is a respiratory disease that affects more than 300 million people world-wide. It is a chronic inflammatory disease of the airways that gives rise to bronchial hyper-responsiveness and airway obstruction thus leading to symptoms such as wheeze, cough, breathlessness and chest tightness ${ }^{[1]}$. Epidemiological data on large population-based studies demonstrate that the prevalence of asthma is approximately 5\%-10\% in Western countries ${ }^{[2-6]}$. However, asthma, and in particular severe asthma, is increasingly recognized as a heterogeneous disease consisting of several phenotypes ${ }^{[7,8]}$. While existing therapies are effective for the majority of asthmatics, treatment for individuals with more severe asthma are often ineffective. The

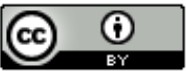

(C) The Author(s) 2019. Open Access This article is licensed under a Creative Commons Attribution 4.0 International License (https://creativecommons.org/licenses/by/4.0/), which permits unrestricted use sharing, adaptation, distribution and reproduction in any medium or format, for any purpose, even commercially, as long as you give appropriate credit to the original author(s) and the source, provide a link to the Creative Commons license, and indicate if changes were made.M

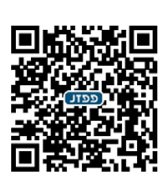


complexity of the disease phenotypes necessitates the definition of pathophysiological mechanisms driving different subtypes of asthma, i.e., classified as a disease endotype ${ }^{[7]}$.

In recent years, the role of non-coding RNAs has emerged as an important area of research. Particularly, microRNAs (miRNAs) are prime examples of regulatory molecules with roles in a variety of different diseases such as cancer, multiple sclerosis, diabetes, and pulmonary disease ${ }^{[9-14]}$. miRNAs target messenger RNA (mRNA) transcripts through binding of conserved seed sequences. A single miRNA can regulate many different mRNAs in a spatial and temporal manner. Additionally, several miRNAs may target the same mRNA transcript, although not necessarily under the same conditions. Regulation occurs mainly through the silencing of a transcript by translational repression or targeting of the particular mRNA for decay ${ }^{[15,16]}$. For more details regarding metazoan miRNA biogenesis, targeting, and function, several excellent reviews have been recently published ${ }^{[17-19]}$. Although miRNAs are not new players in disease development, their role as regulatory molecules in asthma is a relatively new field of study. miRNAs are extremely stable in a variety of bodily fluids such as blood, urine, sputum, exhaled breath condensates, serum and plasma, facilitating their study via non-invasive methods ${ }^{[20-24]}$. Due to the ever growing list of miRNAs being discovered and verified, the complexity of miRNA regulation is far from being unraveled.

Although there have been several advancements in our knowledge of asthma, particularly in the control and treatment of symptoms, many questions remain regarding the molecular mechanisms of the disease. In this review, we aim to discuss the current knowledge regarding the role of miRNAs in asthma, from mouse to man.

\section{Evidence for miRNA regulation in asthma models}

Animal models are useful tools for the study of asthma pathogenesis ${ }^{[25]}$. However, no mouse model encompasses all features of asthma including severe asthma. For instance, mice do not spontaneously develop a disease that resembles human asthma ${ }^{[26]}$. To mimic the human disease, both ovalbumin (OVA)induced and house dust mite-induced murine models of allergic airway inflammation were developed ${ }^{[27,28]}$. As a consequence, the human allergic asthma phenotype has been the main asthma subtype studied in the mouse models. Type 2 allergic immune responses in humans are mediated by the type 2 cytokines, interleukin (IL)-4, IL-5 and IL-13, which also occurs in the mouse model ${ }^{[29]}$. CD4+ T-helper 2 cells (Th2 cells) are thought to play a central role in regulating phenotypes of allergic asthma; however, during the last decade innate lymphoid cells (ILCs) have also been discovered. In addition to Th2 cells, ILC2 cells produce significant amounts of the type 2 cytokines IL- 5 and IL-13 ${ }^{[30-32]}$.

\section{T cells}

Cell-specific miRNA expression patterns in murine models have suggested a role for miRNAs in lineage commitment and $\mathrm{T}$ cell effector functions ${ }^{[33,34]}$. Deletion of essential components of the miRNA biosynthesis pathway has revealed a critical role for miRNAs in $\mathrm{T}$ cell activation and function ${ }^{[35]}$. Interestingly, in $\mathrm{T}$ cells lacking Dicer, a key protein in the biosynthesis of miRNAs, an enhanced differentiation towards Th cell and cytokine production was seen. This suggests an important role for miRNAs in naïve $\mathrm{T}$ cell homeostasis. However how these processes are regulated are still under further investigation.

Recent studies have identified that the miR-23 27 24 cluster controls T cell differentiation and function ${ }^{[36]}$. By combining loss and gain-of-function genetic approaches, the authors demonstrated that the miR23 27 24 cluster regulated Th2 differentiation and effector function in vivo in mice. Thus, two independent reports revealed that miR-24 and miR-27 inhibited Th2 differentiation and IL-4 production ${ }^{[36,37]}$. Deletion of these miRNAs promoted Th2-dependent responses in vivo in an OVA-induced allergic asthma model. miR24 directly targeted the $3^{\prime}$-untranslated region (3' UTR) of IL-4 whereas miR-27 was shown to repress GATA binding protein 3 (Gata3), Ikaros family zinc finger 1 and nuclear factor of activated T cells 2 (Nfatc2), all of which are positive regulators of IL-4 expression. Interestingly, induced expression of miR-24 promoted Th1 and Th17 differentiation and induced T regulatory cells ${ }^{[36]}$. These data suggested that individual miRNAs 
within a cluster could work in an antagonizing, rather than cooperative, manner. Similarly, miR-146a deficient mice have been shown to display increased airway inflammation and type 2 immune response in a mouse model of house dust mite (HDM)-induced asthma ${ }^{[38]}$. Indeed, a polymorphism in miR-146a was found to be associated with human asthma ${ }^{[39]}$.

Another potentially inhibitory group of miRNAs is the let-7 family. These miRNAs act as regulators of IL-13 expression by direct targeting the $3^{\prime}$ UTR of the IL-13 transcript ${ }^{[40]}$. Furthermore, induced levels of IL-13 in cultured $\mathrm{T}$ cells were shown to inversely correlate to let-7 levels. In a mouse model of allergic airway inflammation, let-7 family members were down-regulated and intranasal administration of let-7 mimics led to reduction of IL-13 expression and resolution of allergic airway inflammation ${ }^{[4]}$. Although the two research teams came to different conclusions regarding the role of let-7, Kumar et al. ${ }^{[41]}$ speculated where the two studies may have differed from each other. First of all, differences in methodology may have led to some discrepancies as the treatment route - systemic vs. local could have an impact on the efficacy of the miRNA. Additionally, there may be a negative feedback loop with the miRNA processing enzyme Dicer, leading to the anti-inflammatory effects of let-7 inhibition. Furthermore, in vitro data highlighted the complexity of miRNAs as the endogenous abundance of different let-7 family members as well as the functional redundancy of the IL-13 3' UTR, likely played a role in the effectiveness of target binding and downregulation ${ }^{[4]]}$. However, in an additional study, let-7 inhibitors also decreased allergic airway inflammation; thus, arguing for a complexity in the miRNAome in these models, and suggesting a pro-inflammatory role of let-7 in allergic airway inflammation and asthma ${ }^{[40]}$.

One of the most studied miRNAs is miR-155, which is highly conserved across metazoans ${ }^{[42]}$. Earlier studies of this miRNA showed that CD4+ T cells lacking miR-155 had a tendency to undergo spontaneous Th2 differentiation under normal conditions ${ }^{[43,44]}$. Indeed, overexpression of miR-155 in CD4+ T cells promoted Th1 differentiation in vitro, suggesting a role for miR-155 in T cell polarization. In contrast to these studies, we and others have shown that miR-155 promotes type 2 inflammation in vivo in models of allergic asthma, suggesting a fine tuning, context dependent regulation by this miRNA. Indeed, miR-155 was significantly upregulated in the lung of both acute and chronic models of allergic asthma ${ }^{[45,46]}$. Additionally, allergen challenged miR-155 deficient mice had diminished Th2 responses and airway eosinophilia, which was related to an increased expression of the transcription factor PU.1 in lung draining lymph nodes ${ }^{[46]}$. Elevated PU.1 is probably one reason for the suppressed Th2 responses in miR-155 deficient mice since PU.1 is both a direct target of miR-155 and a negative regulator of GATA-3, an important transcription factor for Th2 cells. In addition, other in vivo studies have also demonstrated that miR-155 is required for type 2 immunity. In a mouse model of HDM-induced asthma, miR-155 was shown to be required for HDM-induced hyperresponsiveness and cell recruitment, mediated partially through direct targeting of sphingosine-1-phosphate receptor $1(\operatorname{Sp} 1 \mathrm{r} 1)^{[38]}$.

Specific miRNAs have been found to participate in polarization of adaptive type 2 immune responses. One such miRNA is miR-21, which has been shown to be upregulated in models of allergic asthma. In particular, miR-21 was shown to regulate the Th1 and Th2 balance by targeting IL-12p35 expression ${ }^{[47]}$. Overexpression of miR-21 promoted in vivo differentiation of Th2 cells. Furthermore, allergen-challenged miR-21 deficient mice had reduced airway eosinophilia and decreased levels of Th2 cytokine, IL-4 with concomitant increased levels of the Th1 cytokine, interferon (IFN)-gamma.

\section{ILC2s}

In addition to Th2 cells, the ILC2s also produce type 2 cytokines that drive allergic airway inflammation. These cells respond to the epithelial derived cytokines IL-33, IL-25 and thymic stromal lymphopoietin and have been suggested to play a significant role both in the initiation and the maintenance of chronic airway inflammation ${ }^{[48,49]}$. Indeed, these cells have been shown to be present in sputum and in bronchoalveolar 
lavage in human asthma ${ }^{[0,51]}$, however, the exact mechanisms underlying ILC2 development and function are currently unknown. One recent study demonstrated that the miR-17 92 cluster regulates different aspects of ILC2 biology. Mice deficient in the miR-17 92 cluster in ILC2s displayed reduced lung inflammation following papain exposure ${ }^{[52]}$. Furthermore, the miR-17 92 cluster member miR-19a promoted IL-5 and IL-13 production in ILC2s and inhibited several targets including suppressor of cytokine signaling 1 (SOCS 1 ) and tumor necrosis factor alpha induced protein 3 (Tnfaip3), both of which are known negative regulators of IL-5 and IL-13 production. These findings clearly demonstrate miRNAs important regulators of ILC2 biology in addition to T cells. We have further demonstrated in an OVA-model of allergic airway inflammation that miR-155 deficient mice display impaired numbers of ILC2s in the airways and that miR155 deficiency affects IL-33 signaling ${ }^{[45]}$. Thus, miR-155 was shown to be required for IL-33-induced ILC2 expansion and function in vivo. Indeed, IL-33 stimulation upregulated miR-155 in wild type ILC2s more than 10-fold and ILC2s derived from miR-155 deficient mice produced less IL-13 upon IL-33 stimulation compared to wild type derived ILC2s. Interestingly, in a recent study, miR-155 was shown to regulate ILC2 survival following activation by protecting ILC2s from apoptosis to promote type-2 immunity. By using mixed bone marrow chimeras, the authors clearly demonstrated that an ILC2-intrinsic expression of miR155 is required to protect ILC2s from apoptosis, confirming our study that miR-155 is required for ILC2 expansion in vivo $^{[53]}$.

\section{The airway}

Both miR-126 and miR-145 have been shown to be expressed in the airway wall. One of the first studies describing functionality of a miRNA in an animal model of asthma was by Mattes et al. ${ }^{[54]}$ demonstrating a significant role for miR-126 in HDM-driven allergic airway inflammation. In their study, miR-126 was shown to be upregulated in the airway wall following HDM challenge and inhibition of miR-126 by miR-126 antagomirs, reducing the effector functions of Th2 cells and the development of allergic airway inflammation ${ }^{[54]}$. Similarly, inhibition of miR-145 attenuated the production of IL- 5 and IL-13 by Th2 cells, eosinophil recruitment, mucus hypersecretion and airway hyper-responsiveness in HDM-induced allergic inflammation ${ }^{[55]}$. miR-106a has been shown to inhibit the anti-inflammatory cytokine IL-10 expression in both lymphoid and myeloid cells. Sharma et al. ${ }^{[56]}$ were among the first to describe the targeting of IL-10 by miR$106 \mathrm{a}$ and its role as a potential therapeutic by reversing the asthmatic phenotype. Administration of miR-106aspecific antagomir locally to the airways in an OVA-model of allergic asthma reduced inflammation and Th2 responses, airway hyper-responsiveness, goblet cell metaplasia and subepithelial fibrosis ${ }^{[56]}$.

\section{Evidence for miRNAs regulation in steroid-insensitive asthma models}

miRNA-directed therapeutics for asthma and allergic diseases are areas of investigations. Several studies as mentioned above, clearly demonstrate that miRNAs are capable of altering both airway inflammation and airway hyper-responsiveness in in vivo studies of allergic eosinophilic asthma models. However, most of the studies conducted are in acute models of allergic asthma - steroid-insensitive asthma is often associated with a non-eosinophilic phenotype- and infection-driven forms even though subgroups of eosinophilic inflammation exist. In a mouse model of steroid-resistant asthma Li et al. ${ }^{[57]}$ demonstrated that miR9 antagonism restored dexamethasone sensitivity. miR-9 expression was shown to be increased in lung macrophages and miR-9 directly targeted protein phosphatase $2 \mathrm{~A}$ and thus interfered with glucocorticoid signaling ${ }^{[57]}$. Interestingly, miR-9 was also demonstrated to be increased in sputum from neutrophilic asthma, but not in eosinophilic asthma. In another study of an infection-induced severe steroid-insensitive experimental asthma model, miR-21 was shown to act upstream phosphoinositide-3-kinase (PI3K) signaling pathway. miR-21 targeted phosphatase and tensin homolog (PTEN), thus amplifying PI3K-dependent activity. Treatment with miR-21-specific antagomir or pan-PI3K inhibitor reduced PI3K activity and restored histone deacetylase expression and led to suppression of airway hyper-responsiveness and steroid sensitivity to allergic airway disease, highlighting miR-21 as a novel therapeutic target for this asthma group ${ }^{[58]}$.

\section{PEDIATRIC ASTHMA}

The early work in mouse models has led the way for studies to be performed using human subjects. It was 
recently reported that up to $20 \%$ of school aged children in Europe have asthma ${ }^{[2]}$. Asthma often manifests during childhood, with males being more affected than females. Additionally, there is a strong link between childhood asthma and atopy and Th2-based immunological responses ${ }^{[59]}$. To date, there have been very few studies examining the role of miRNAs in the pediatric asthma population. Thus, studies to understand the causes and molecular mechanisms of the disease are important for future treatments and diagnoses.

\section{miRNAs in lung development}

Even before birth, miRNAs play a major role in the developing lung. During organogenesis the miRNA processing enzymes Dicer and Ago have been shown to be greatly expressed in the branching regions of the lung, suggesting that these areas are major sites of miRNA regulation ${ }^{[60]}$. These findings were later expanded when array studies examining the miRNA, mRNA and protein expression during murine lung organogenesis were performed. Dong et al. ${ }^{[61]}$ were able to show that changes in miRNA expression appeared to be a prominent mechanism during lung development with miRs-21, -167 , and -198 being differentially expressed. Shortly thereafter, differential expression of several miRNAs during development in both the mouse and human lung were observed ${ }^{[62]}$. Overall, the expression patterns between mouse and human tissue was similar, signifying that the expression pattern of miRNAs in lung development is evolutionarily conserved. Furthermore, in transgenic mice where the miR-17 92 cluster was overexpressed, Lu et al. ${ }^{[63]}$ observed that lung epithelial progenitor cells were unable to differentiate, thus, suggesting a role for miRNAs in promoting cell differentiation in lung cells. Using rat lung at different developmental stages, Bhaskaran et al. ${ }^{[6]]}$ showed the temporal nature of miRNA expression. They focused on miR-127, which was highly expressed in late stage lung development. Further analysis of miR-127 showed a shift of this miRNA during development from mesenchymal to epithelial cells and overexpression of miR-127 in fetal lung cultures caused improper bud formation, suggesting the importance of this miRNA in lung development. With the knowledge gained of differential miRNA expression during lung development, perhaps we can start to pinpoint early signs of potential disease or abnormal embryonic development via the miRNA signatures in amniotic fluid, placenta or cord blood.

\section{Comparisons of pediatric asthma to murine models}

In an early study, Liu et al ${ }^{[65]}$ performed microarrays to identify miRNA expression differences between blood lymphocytes in young asthmatic and non-asthmatic children, where 36 miRNAs were significantly upregulated and 47 miRNAs were significantly downregulated. They then went on to compare miRNAs found in asthmatic children with OVA-induced murine models and found that miR-221 and miR-485$3 p$ were upregulated in both instances. Furthermore, using in silico analysis, they found that a common predicted target of both miRNAs, sprouty-related, EVH1 domain-containing protein 2. This gene was later found to be downregulated in the murine asthma model, thus suggesting a valid miRNA-mRNA interaction that may have important implications in the development or persistence of childhood asthma. In order to determine biomarkers for young children with potential asthma, Jiang et al ${ }^{\left[6{ }^{66]}\right.}$ examined children with recurrent wheeze. Recurrent wheeze is regarded as an important risk factor for developing asthma and so a biomarker to help identify asthma, which would be helpful in early diagnosis. Plasma was collected from 140 children ranging from 0 to 12 years of age, with half having recurrent wheeze or asthma and half acting as controls. Eleven miRNAs were chosen based on their association to asthma and miR-21 and miR-26a proved to be significantly different between the control and recurrent wheeze group. Moreover, this increase in miR21 and miR-26a expression could be replicated in the plasma and bronchoalveolar lavage fluid (BALF) of rats with both acute and chronic pulmonary inflammation. Thus, these miRNAs could be of interest for future studies in the development of asthma in children.

\section{Circulating miRNAs as potential biomarkers in pediatric asthma}

Several studies have addressed the potential for miRNAs to act as biomarkers in childhood asthma cohorts. Due to the ease of collection, blood has often been used to identify miRNAs as potential biomarkers in 
pediatric asthma. miR-21 was previously described as increased in allergic airway models in mice ${ }^{[47,67]}$, thus Sawant et al. ${ }^{[68]}$ set out to determine if this was also true in asthmatic children. Using serum samples, they found that miR-21 was specifically increased in children with asthma and that this increase was not correlated to IgE levels, indicating that miR-21 may be usable as a biomarker for asthma independent of atopic status. Other recent studies have also shown the potential of miR-21 as a biomarker in pediatric asthma, but this time in plasma ${ }^{[69]}$. Hammad et al. ${ }^{[69]}$ explored the potential of two suggested asthma biomarker miRNAs and whether they played a role in predicting asthma outcome following treatment with inhaled corticosteroids (ICS). They found that both miR-21 and miR-146a were upregulated in plasma from asthmatic children and showed a correlation to forced expiratory volume in 1 second following ICS treatment, suggesting that they may play a role in determining the outcome of asthma after treatment. As mentioned above, miR-21 was also found to be associated with very young children with recurrent wheeze ${ }^{[66]}$. As pulmonary function tests are difficult to perform in young children ${ }^{[70]}$, it would be interesting to see if high miR-21 and -146a levels can be used as a predictor of future lung function.

Although most studies in pediatric asthma use a general "allergic" definition for their subjects, Dong et al. ${ }^{[1]}$ focused specifically on dust-mite induced mild asthmatic children. The group isolated total RNA from peripheral blood of 124 age- and gender-matched asthmatic and non-asthmatic children and performed a microarray-based analysis to determine altered expression levels. They went on to identify 122 differentially expressed miRNAs and found three downregulated miRNAs, miR-22-3p, -513a-5p, -625-5p, to be not only statistically significant, but functionally linked to inflammation by web-based bioinformatics analysis. Through a series of filtering processes, CBL, PPARGC1B and ESR1 were identified targets of the three aforementioned miRNAs. Furthermore, the predicted target genes were differentially expressed in their asthmatic group and were associated with $\mathrm{PI} 3 \mathrm{~K}$ and nuclear factor $\kappa \mathrm{B}(\mathrm{NF}-\kappa \mathrm{B})$ signaling pathways as well as $\mathrm{T}$ and $\mathrm{B}$ cell differentiation and inflammatory factor signaling using Kyoto Encyclopedia of Genes and Genomes and Gene Ontology analysis. Additionally, they showed a correlation between these three miRNAs and their predicted mRNA targets, as well as a suggestion for how they regulate their predicted signaling pathways, thus, putting forth potentially important mechanistic roles for these miRNAs in pediatric asthma. Again, apart from studying pediatric asthma as mainly an allergic disease, Midyat et al. ${ }^{[72]}$ explored the relationship between miRNA expression and the severity of childhood asthma. Using a relatively wide age range (6-18 years), approximately 100 asthmatic children, half exhibiting intermittent asthma and half exhibiting severe asthma, were examined in comparison to age-matched controls. miRNA expression from blood lymphocytes were examined by microarray and ten miRNAs were found to significantly increase their expression as asthma severity increased. miRNAs let-7e, miR-98 and miR-497 were found to be significantly increased in the intermittent asthma group compared to controls, but not severe asthma. As mentioned above, the let-7e/miR-98 family has been suggested to target the $I L 13$ gene ${ }^{[40]}$. Together, these findings further drive home the complexity of the asthmatic phenotype, with differing asthma severity exhibiting alterations to miRNA repertoire. Finally, Nakano et al. ${ }^{[73]}$ took an alternative approach to identifying potential miRNA biomarkers. They focused on the mRNA vascular endothelial growth factor A (VEGFA), which was identified as a key molecule in asthma pathogenesis and had previously been shown to be overexpressed in the serum and sputum of asthmatic subjects of all ages ${ }^{[74-76]}$. Through in silico analysis, the group selected 12 miRNAs predicted to bind the 3' UTR of VEGFA and examined their expression in CD4+ T cells, which are a major serum source of VEGFA, from pediatric subjects. They found that three miRNAs, miR-15a, -15b, and -20a, exhibited lower expression when VEGFA levels were increased, but only miR-15a and VEGFA were significantly correlated. Finally, they showed through luciferase reporter assays that the binding of miR-15a led to decreased expression of VEGFA, thus reporting one of the first instances of miRNA-target binding in pediatric asthma patients.

Recently, several studies from the Tantisira group, using the Childhood Asthma Management Program (CAMP) cohort of asthmatic children, have shown the potential for not only array screening for miRNAs as biomarkers, but the potential downstream applications and analysis needed to move the asthma field 
forward $^{[77-79]}$. Using serum samples from the CAMP cohort of 160 individuals, as well as fetal lung cells, Kho et al. ${ }^{[79]}$ explored correlations between serum miRNA expression and a variety of parameters including: lung function, sex and association with lung development. Furthermore, they compared their findings to other studies performed in human subjects or cell lines to determine their potential as asthma biomarkers. Twentytwo miRNAs were shown to associate with lung function parameters and of those 22, nine (miR-139-5p, -15b5p, 186-5p, 342-3p, 374a-5p, 409-3p, 454-3p, 660-5p, and -942-5p) were shown to associate with males alone and three (miR-1290, -142-3p, and 191-5p) with females alone. Additionally, seven (miR-126-3p, -203a-3p, -26a-5p, $-30 b-5 p,-342-3 p,-409-3 p$ and $-942-5 p$ ) of those 22 miRNAs associated with lung function were also associated with gestational age. They then performed ontology analysis to examine pathways and potential genes in which these miRNAs play a role. Pathways important in asthma pathogenesis including PPAR signaling and respiratory system development were enriched suggesting potential circulating biomarkers associated with lung function. Another study using the CAMP cohort examined the association between circulating miRNAs in serum and airways hyper-responsiveness ${ }^{[77]}$. They found a significant association of miR-296-5p, -548b-5p, -138-5p, -16-5p, -1227-3p, -30d-5p, -203a-3p, and -128-3p with decreasing airway hyper-responsiveness. They went on to confirm the results using two of the miRNAs known to be highly expressed in airway smooth muscle cells, miR-16-5p and -30d-5p. When they used mimics of miR-16-5p and -30d-5p in vitro, they found altered cell growth and diameter of the cells compared to the scrambled controls. Lastly, they found through in silico interaction and pathway analysis that miR-16-5p appeared to be a hub connecting many of the other identified miRNAs and targets. Furthermore, many of the miRNAs found in this study have been previously identified as asthma related, which strengthened their findings. Recently, Kho et al ${ }^{[78]}$ performed the first study to investigate the prediction of asthma exacerbations by circulating miRNAs. A combination of three miRNAs: miR-146b-5p, -206 and -720 were sufficient to provide predictive power to the clinical model of asthma exacerbation and the combination of miRNA and clinical score of asthma exacerbations was superior than either measurement on its own. Thus, the combination of a well-defined cohort, various screening techniques, and bioinformatics analysis has yielded a wealth of new information about miRNA associations with childhood asthma and opened the door for a cascade of future studies.

Although this collection of work has paved the way for miRNAs as potential biomarkers for asthma, all of the above mentioned studies were performed on relatively small cohorts for the miRNAs to be considered "true" biomarkers. Additionally, mechanistic studies of asthma on children appears to be relatively rare, likely due to the lack of more invasive methods of sampling (e.g., biopsies). Endotyping in childhood asthma cohorts is also relatively rare, so few detailed studies have been performed on non-allergic asthmatic pediatric cohorts ${ }^{[80]}$. Furthermore, the age range of the aforementioned studies was between 0 and 18 years old. Due to the heterogenic nature of asthma and the bodily-hormonal and physical-changes that occur throughout childhood, which most likely affect the development of the disease, detailed patient characteristics would be greatly needed to determine whether study groups are comparable to one another.

\section{MIRNA IN ADULT ASTHMA}

Evidence for miRNA involvement in asthma comes largely from murine models, but recently a number of studies have been performed investigating human samples obtained from asthmatics. However, as adult asthma is now considered a heterogeneous disease entailing a number of different phenotypes ${ }^{[81]}$, we attempted to sort these studies based on their asthma characteristics if that information could be retrieved from the study. Is it possible for miRNAs to be used to aide in this characterization and further contribute to the understanding of the underlying pathogenesis?

\section{Allergic asthma}

Most asthmatics belong to the allergic asthma phenotype and often atopic and allergic asthma originates in early childhood, but it can also occur in adulthood. However, based on the information given in the 
studies reviewed, a distinction between early onset and late onset allergic asthma cannot be distinguished. Allergic asthma is usually described as a type 2 driven disease with increased type 2 cytokine production such as IL-4, IL-5 and IL-13 and increased numbers of eosinophils as well as increased IgE levels. miR-155 has been shown to be down-regulated in allergic asthmatics in exhaled breath condensates ${ }^{[82]}$. We observed a similar downregulation of miR-155 in lymphocytes isolated from induced sputum from allergic asthmatics in pollen season compared to out of season ${ }^{[83]}$. miR-155, together with miR-18a, miR-126, let-7e and miR224, were also downregulated in nasal mucosa of allergic asthmatics compared to controls even when no markers of type 2 inflammation were detected ${ }^{[84]}$. Fekonja et al ${ }^{[85]}$ utilized a different approach to examining miRNAs by searching different databases to find asthma associated miRNAs and their target interactions. They suggested 4 central molecules including miR-155, miR-21, IL-13 and Sma- and Mad-related protein 2 in asthma, although they did not distinguish between asthma phenotypes ${ }^{[85]}$. In contrast to miR-155, miR-19a was found to be increased in BALF Th cells and was shown to promote type 2 cytokine production by direct targeting of the inositol phosphatase PTEN, the signal inhibitor SOCS1, and the deubiquitinase A20 which are inhibitors of nuclear factor NF- $\mathrm{KB}$, signal transducer and activator of transcription and PI3K pathways ${ }^{[8]}$. miR-19a has also been described to enhance proliferation of bronchial epithelial cells in asthma by targeting the transforming growth factor bR2 (TGFbR2) gene ${ }^{[87]}$. Moreover, reduced miR-19a was shown to lead to the constitutive high expression of protein arginine methyltransferase 1 in airway smooth muscle cells leading to enhanced remodeling ${ }^{[88]}$. Unfortunately, in the aforementioned study no description of the asthma subtype was available. Furthermore, the three studies described above investigated different cell types, thus it is unknown if these findings hold true throughout the body. Another important miRNA in allergic asthma is miR-98 due to its ability to suppress thrombospondin 1 in B cells upon exposure to IL-1, which, in turn impairs the immunosuppressive function of $\mathrm{B}$ cells on other effector immune cells ${ }^{[89]}$. Additional miRNAs reported to be upregulated in allergic asthma were miR-498, -187, -874, -886-3p, and -143 this time found in nasal mucosa ${ }^{[84]}$. In a more recent study, miR-143-3p was shown to control TGF- $\beta 1$-induced cell proliferation and extracellular matrix production in airway smooth muscle via negative regulation of the NFATC $1^{[90]}$. In both plasma and airway epithelial cells, miR-181b-5p was associated with airway eosinophilic inflammation in asthma and was suggested to regulate proinflammatory cytokines expression by targeting osteopontin, a multifunctional extracellular matrix protein. Plasma miR-181b-5p was increased after ICS treatment and dexamethasone restored IL-13-induced miR-181b-5p down-regulation and suppressed IL-13-induced osteopontin in epithelial cells ${ }^{[91]}$.

As previously mentioned, miRNAs are emerging as biomarkers important in better understanding asthma pathogenesis and aiding in the discrimination of various asthma phenotypes. Panganiban et al ${ }^{[92]}$ performed a study comparing differentially expressed miRNA in plasma samples from asthmatic patients, nonasthmatic patients with allergic rhinitis (AR) and non-allergic non-asthmatic subjects to establish whether miRNA could be used to characterize or subtype asthmatic patients. They reported 30 miRNAs out of 420 that were statistically different between the three groups which they then classified into five expression pattern groups. Interestingly, group 2 miRNAs demonstrated expression differences that were unique to asthmatic patients even though $83 \%$ of these patients were also allergic. They found that miR-16, -223-3p, $-148 \mathrm{a}$ and $-146 \mathrm{a}$ were upregulated and miR-299-5p, -570 and -150 were downregulated among asthmatic patients, but no difference was observed between AR and healthy subjects. Target pathways predicted to be regulated by this group of miRNAs suggested the regulation of key components of inflammatory pathways and focal adhesion pathways likely involved in airway basement membrane and airway smooth muscle in asthmatic patients ${ }^{[92]}$. The same group previously described the upregulation of miR-1248 and the downregulation of miR-26a, let-7a, and let-7d in serum from allergic asthmatic patients compared to controls. They also showed that miR-1248 interacted with IL-5 and served as a positive regulator, as opposed to the deleterious effects seen by most miRNAs, by increasing IL-5 expression ${ }^{[93]}$. Milger et al ${ }^{[94]}$ utilized a separate approach by first identifying murine miRNA candidates which later were studied in plasma samples obtained from human allergic asthma patients. This study revealed three miRNAs common for both human 
samples and in the murine allergic model; the previously described miR-223-3p ${ }^{[92]}$, and miR-21 ${ }^{[85]}$ and a new miRNA involved in asthma, miR-27a ${ }^{[94]}$. Vesicle entrapped miRNAs in both BALF and in exhaled breath condensates in allergic asthmatics showed decreased expression let-7 family members as well as the miR200 family which has been previously shown to regulate epithelial mesenchymal transition and is implicated in airway remodeling ${ }^{[95]}$. Additionally, a recent publication found that miR-200b/c was downregulated in BALF from young adults, which could be recapitulated in two different mouse models of allergic airway inflammation ${ }^{[96]}$. Furthermore, miR-200b/c was shown to target IL-33 in the airways, suggesting a new regulator of IL-33 in asthmatic airways.

\section{Neutrophilic asthma}

Neutrophilic asthma is debated as a specific phenotype. Neutrophilia is generally seen in corticosteroidtreated patients and is often associated with severe asthma ${ }^{[81,97]}$.

Maes et al. ${ }^{[98]}$ used sputum supernatant from patients with severe asthma, mild-to-moderate asthma, and healthy subjects. They found three miRNAs, miR-223-3p, -142-3p and -629-3p increased in severe asthma and associated with neutrophilic airway inflammation. In bronchial biopsies, miR-223-3p, a miRNA also described to be altered in allergic asthma, was found to be co-localized with neutrophil elastase positive cells in contact with miR-629-3p expressing epithelial cells. Furthermore, transfection of primary human bronchial epithelial cells with miR-629-3p mimics generated increased levels of the neutrophil chemoattractant IL-8 and provided a mechanistic link between increased miR-629-3p and airway neutrophilia ${ }^{[98]}$. In a recent study, miR-199a-5p was found to be increased in plasma and induced sputum from neutrophilic asthma and negatively correlated to pulmonary function. Peripheral blood derived neutrophils, lymphocytes and macrophages stimulated by lipopolysaccharide in vitro showed increased miR$199 \mathrm{a}-5 \mathrm{p}$ specifically in neutrophils ${ }^{[99]}$.

\section{Severe asthma}

Severe asthma is described as a difficult-to-treat asthma often needing increased medication such as oral steroids. Neutrophils and/or eosinophilia have been suggested to be a common occurrence, but it is likely that several subtypes of severe asthma exist ${ }^{[8,97,100]}$.

Reduced let-7a levels in bronchial biopsies of patients were suggested as a biomarker for severe systemic glucocorticoid therapy-resistant asthma ${ }^{[101]}$, but were also found to be reduced in the serum from allergic asthmatics $^{\left[{ }^{93]}\right.}$. Rupani et al. ${ }^{[102]}$ showed that the expression of toll-like receptor 7 (TLR7), crucial for responses to single-stranded RNA viruses, was significantly deficient in alveolar macrophages from severe asthmatics. TLR7 deficiency in these macrophages was found to be regulated by increased expression of miR-150, -152, and -375. Furthermore, blocking these miRNAs increased TLR7 expression and restored IFN responses to virus ${ }^{[102]}$. Activation of peripheral blood CD8+ T cells correlated with downregulation of miR-146a/b and miR-28-5p in severe asthmatics ${ }^{[103]}$. In contrast, airway smooth muscle cells from asthmatics demonstrated increased expression of miR-146a upon stimulation, which negatively regulated cyclooxygenase- 2 and IL-1 $\beta$ shown by loss of function studies ${ }^{[104]}$. Another study using airway smooth muscle cells from severe asthmatics showed increased proliferation and higher IL-6 secretion in response to TGF- $\beta$ stimulation compared to cells obtained from mild asthmatics and healthy controls. In addition, miR-221 was significantly increased in severe asthmatics and inhibition of miR-221 resulted in reduced proliferation and IL-6 release ${ }^{[105]}$. Autophagy plays critical roles in airway inflammation and fibrosismediated airway remodeling and many factors including proinflammatory cytokines and inflammation related pathways are involved in the process. In this study, comprised of plasma samples from asthmatics ranging from mild to severe, decreased levels of miR-34/449 were shown. In vitro experiments using lung epithelial cells further showed that miR-34/449 modulated insulin growth factor binding protein-3 mediated autophagy activation ${ }^{[106]}$. Interestingly, an earlier study of airway epithelial cells found decreased expression 
in members of the miR-34/449 family in asthmatic compared to healthy subjects, and miR-34/449 was found to regulate epithelial cell differentiation in vitro ${ }^{[107]}$.

\section{The asthma-chronic obstructive pulmonary disease overlap syndrome}

The asthma-chronic obstructive pulmonary disease (COPD) overlap syndrome (ACOS) is a relatively new definition and has clinical features of both asthma and COPD. It is likely that for ACOS, as for asthma and COPD, a range of different underlying mechanisms will be identified.

Thus far, only one study has investigated the miRNA expression pattern in ACOS. Both miR-145 and miR338 were increased in serum and sputum supernatant from the disease compared to healthy subjects. They could not find any differences between the expression of miRNA-145 and miRNA-338 in ACOS patients compared to asthma or COPD patients. The authors considered this finding as a confirmation that ACOS presents some overlapping characteristics between both diseases ${ }^{[108]}$.

\section{Asthma phenotype not defined}

CD4+ $\mathrm{T}$ cells from asthmatics demonstrated a negative correlation between miR-145 and runt-related transcription factor 3 (RUNX3) mRNA. Using miR-145 mimics and inhibitors the study revealed that miR145 functions as a regulator of Th1/Th2 balance by targeting RUNX $3^{[109]}$. Increased expression of miR-323$3 p$ in peripheral blood mononuclear cells from patients with asthma was associated with IL-22 production in T cells. miR-323-3p was found to act in a negative feedback loop to control the production of IL-22 in IL-22/IL-17 producing $\mathrm{T}$ cells and thereby affecting $\mathrm{T}$ cell responses in asthma ${ }^{[110]}$. Network analysis was used to identify a novel asthma-associated gene. The top ranked predicted target of the highly downregulated miRNA-203 in asthmatic cells was the aquaporin 4 (AQP4) gene. Its expression was confirmed to be significantly higher in bronchial epithelial cells from patients with asthma. Up-regulation of AQP4 in the bronchial epithelial cells of patients with asthma may represent a mechanism, by which the lung is attempting to clear excessive fluid ${ }^{[111]}$.

\section{FUTURE PERSPECTIVES}

As miRNAs are differentially expressed in various cells and time-points, there is much interest to use them in the clinic as biomarkers for asthma. Indeed, various studies have used mouse models and human subjects to explore the possibility of miRNA biomarkers in asthma [Table 1]. miRNAs are especially well suited for the biomarker role as they have been shown to be extremely resistant to different conditions (such as $\mathrm{pH}$, heat, and freeze-thaw), likely due to their protection by various RNA binding proteins and/or the inclusion into vesicles ${ }^{[112-114]}$. Furthermore, miRNAs have been found in virtually every tissue and bodily fluid examined, meaning that they can be collected using both invasive and non-invasive methods. To date, a few therapies using miRNA agonists are in clinical trials, mostly for the treatment of cancers ${ }^{[115-119]}$. As miRNAs become bigger players in the asthma field, specific signatures and biomarkers to better define the disease may lead to work to develop more directed therapies for future generations.

The current research direction in the asthma field in relation to miRNAs appears to be in the form of data generation and a search for biomarkers. Although this generation of data is critical for advancement in the field, there must be subsequent steps taken to validate these findings. Algorithms and machine learning are an excellent second step to understand if there is a relationship between asthma and the miRNA(s) in question, but one must take care to ensure that subject samples are utilized as well. It does no good for a perfect relationship, as predicted by modeling, if that cannot be replicated in vivo. Several open access programs are now helping researchers to better predict the targets of their miRNA of interest or the pathways that they may be affecting ${ }^{[85,120-123]}$. Unfortunately, a combination of programs must often be used in order to find potential miRNA-mRNA interactions, making it tedious and often unrewarding work during the validation phase. Furthermore, miRNAs can bind a several different targets and several miRNAs can 
Table 1. microRNAs described in this review

\begin{tabular}{|c|c|c|}
\hline Model system & microRNAs & References \\
\hline Murine & $\begin{array}{l}\text { let-7 family, miR-9, miR-21, miR-23-27-24 cluster, miR-26a, miR-27a, miR-126, } \\
\text { miR-127, miR-145, miR-146a, miR-155, miR-167, miR-198, miR-200 family, miR- } \\
\text { 221, miR-223-3p, miR-485-3p }\end{array}$ & {$[33-58,60-67,85,92,94]$} \\
\hline Human: serum & $\begin{array}{l}\text { let-7 family, miR-15a, miR-15b, miR-16, miR-21, miR-26a, miR-30b, miR-30d, miR- } \\
\text { 126-3p, miR-128-3p, miR-138-5p, miR-139-5p, miR-142-3p, miR-145, miR-146b- } \\
\text { 5p, miR-186-5p, miR-191-5p, mir-199a-5p, miR-203a-3p, miR-206, miR-223-3p, } \\
\text { miR-296-5p, miR-338, miR-342-3p, miR-374a-5p, miR-409-3p, miR-454-3p, miR- } \\
\text { 548b-5p, miR-660-5p, miR-720, miR-942-5p, miR-1227-3p, miR-1248, miR-1290 }\end{array}$ & {$[68,73,77-79,93,108]$} \\
\hline Human: plasma & $\begin{array}{l}\text { miR-16, miR-21, miR-26a, miR-27a, miR-34/449, miR-146a, miR-148a, miR-150, } \\
\text { miR-181b-5p, mir-199a-5p, miR-223-3p, miR-299-5p, miR-570 }\end{array}$ & {$[66,69,85,91,92,94,99,106]$} \\
\hline $\begin{array}{l}\text { Human: bronchoalveolar lavage } \\
\text { fluid }\end{array}$ & let-7 family, miR-19a, miR-21, miR-155, miR-200 family & {$[85,95,96]$} \\
\hline $\begin{array}{l}\text { Human: exhaled breath } \\
\text { condensates }\end{array}$ & let-7 family, miR-155, miR-200 family & {$[82,95]$} \\
\hline Human: sputum & $\begin{array}{l}\text { miR-9, miR-15a, miR-142-3p, miR-145, miR-155, miR-199a-5p, miR-223-3p, miR- } \\
\text { 338, miR-629-3p }\end{array}$ & {$[83,98,99,108]$} \\
\hline Human: peripheral blood & miR-22-3p, miR-513a-5p, miR-625-5p & [71] \\
\hline Human: blood lymphocytes & let-7 family, miR-98, miR-221, miR-485-3p, miR-497 & {$[65,72]$} \\
\hline $\begin{array}{l}\text { Human: peripheral blood } \\
\text { mononuclear cells }\end{array}$ & miR-323-3p & [110] \\
\hline Human: CD4+ T cells & miR-15a, miR-15b, miR-20a, miR-145, miR-155 & {$[73,109]$} \\
\hline Human: CD8+ T cells & miR-28-5p, miR-146a, miR-146b & [103] \\
\hline Human: B cells & miR-98 & [89] \\
\hline Human: neutrophils & miR-199a-5p & [99] \\
\hline Human: alveolar macrophages & miR-9, miR-150, miR-152, miR-375 & {$[99,102]$} \\
\hline Human: nasal mucosa & $\begin{array}{l}\text { let-7 family, miR-18a, miR-126-3p, miR-143-3p, miR-155, miR-187, miR-224, miR- } \\
\text { 498, miR-874, miR-886-3p }\end{array}$ & [84] \\
\hline Human: airway smooth muscle & miR-16, miR-19a, miR-30d, miR-143-3p, miR-146a, miR-221 & {$[77,88,90,104,105]$} \\
\hline Human: bronchial epithelial cells & $\begin{array}{l}\text { miR-19a, miR-34/449, miR-106a, miR-126, miR-145, miR-181b-5p, miR-200b/c, } \\
\text { miR-203, miR-629-3p }\end{array}$ & {$[87,91,95,96,98,106,107,111]$} \\
\hline Human: bronchial biopsy & let-7 family, miR-223-3p & {$[98,101]$} \\
\hline
\end{tabular}

The microRNAs (miRNAs) listed are those described in detail within the review. Lists of miRNAs found by array or next generation sequencing were not included

bind a single target and it is still unclear how to best predict these interactions. In the future, we may need to focus on miRNA signatures, i.e., several miRNAs showing a similar phenotype, such as downregulation under a specific stimuli - rather than the effect of an individual species. As more studies are performed, hopefully a large and reliable miRNA interactome database will be developed to further targeted research. Regardless, there is currently a plethora of potential asthma biomarkers identified that would benefit from in-depth mechanistic study to unravel their importance in asthma pathogenesis.

Over the past decade the study of asthma-associated miRNAs has risen dramatically. Although these small regulatory molecules have certainly begun to show their potential to help us better understand the mechanisms of the disease, the field must not forget the basics. Currently, many studies are difficult to compare due to a lack of defined, published patient characteristics. As pointed out above, asthma is not a homogeneous disease and as the field grows, the number of endotypes grows along with it. When performing studies, especially those of a mechanistic nature, it is becoming increasingly important to provide clear and thorough definitions of cohort subjects. Thus, we as co-workers in this field can not only help each other, but work in a smarter fashion to help the patients living with asthma.

\section{CONCLUSION}

Although the miRNA field has been steadily growing over the past twenty years, the role of miRNAs in the development and regulation of asthma remains relatively unexplored. Through the use of animal models, we 
have gained insight into particular facets of the disease and its relevance to humans. Recently, several studies have begun to explore the possibility of miRNAs as biomarkers for asthma, opening the door to a better understanding of the disease as well as the potential for future therapeutics.

\section{DECLARATIONS}

\section{Authors' contributions}

All authors contributed equally to the writing of this manuscript.

\section{Availability of data and materials}

Not applicable.

\section{Financial support and sponsorship}

This work was supported by grants from Herman Krefting Foundation for Asthma and Allergy research, the Swedish Heart and Lung Foundation (20170392), Sahlgrenska University Hospital Foundation, KH Johanssons Foundation and the Swedish Research Council (2017-02302).

\section{Conflicts of interest}

All authors declared that there are no conflicts of interest.

\section{Ethical approval and consent to participate}

Not applicable.

\section{Consent for publication}

Not applicable.

\section{Copyright}

(c) The Author(s) 2019.

\section{REFERENCES}

1. Lambrecht BN, Hammad H. The immunology of asthma. Nat Immunol 2015;16:45-56.

2. GINA. Global strategy for asthma management and prevention. Available from: https://ginasthma.org/wp-content/uploads/2018/04/wmsGINA-2018-report-tracked_v1.3.pdf. [Last accessed on 27 Dec 2018]

3. Lötvall J, Ekerljung L, Rönmark EP, Wennergren G, Lindén A, et al. West Sweden asthma study: prevalence trends over the last 18 years argues no recent increase in asthma. Respir Res 2009;10:94.

4. Lundbäck B, Backman H, Lötvall J, Rönmark E. Is asthma prevalence still increasing? Expert Rev Respir Med 2016;10:39-51.

5. Rönmark E, Lundbäck B, Jönsson E, Jonsson AC, Lindström M, et al. Incidence of asthma in adults--report from the obstructive lung disease in Northern Sweden study. Allergy 1997;52:1071-8.

6. Mincheva R, Ekerljung L, Bossios A, Lundbäck B, Lötvall J. High prevalence of severe asthma in a large random population study. J Allergy Clin Immunol 2018;141:2256-64.

7. Lötvall J, Akdis CA, Bacharier LB, Bjermer L, Casale TB, et al. Asthma endotypes: a new approach to classification of disease entities within the asthma syndrome. J Allergy Clin Immunol 2011;127:355-60.

8. Wenzel S. Severe asthma: from characteristics to phenotypes to endotypes. Clin Exp Allergy 2012;42:650-8.

9. Alipoor SD, Adcock IM, Garssen J, Mortaz E, Varahram M, et al. The roles of miRNAs as potential biomarkers in lung diseases. Eur J Pharmacol 2016;791:395-404.

10. Ameis D, Khoshgoo N, Iwasiow BM, Snarr P, Keijzer R. MicroRNAs in lung development and disease. Paediatr Respir Rev 2017;22:38-43.

11. Booton R, Lindsay MA. Emerging role of MicroRNAs and long noncoding RNAs in respiratory disease. Chest 2014;146:193-204.

12. Peng Y, Croce CM. The role of MicroRNAs in human cancer. Signal Transduct Target Ther 2016;1:15004.

13. Johansson K, Weidner J, Rådinger M. MicroRNAs in type 2 immunity. Cancer Lett 2018;425:116-24.

14. O'Connell RM, Rao DS, Baltimore D. microRNA regulation of inflammatory responses. Annu Rev Immunol 2012;30:295-312.

15. Bartel DP. MicroRNAs: genomics, biogenesis, mechanism, and function. Cell 2004;116:281-97.

16. Ha M, Kim VN. Regulation of microRNA biogenesis. Nat Rev Mol Cell Biol 2014;15:509-24.

17. Bartel DP. Metazoan microRNAs. Cell 2018;173:20-51. 
18. Gebert LFR, MacRae IJ. Regulation of microRNA function in animals. Nat Rev Mol Cell Biol 2019;20:21-37.

19. O’Brien J, Hayder H, Zayed Y, Peng C. Overview of microRNA biogenesis, mechanisms of actions, and circulation. Front Endocrinol (Lausanne) 2018;9:402.

20. Callari M, Tiberio P, De Cecco L, Cavadini E, Dugo M, et al. Feasibility of circulating miRNA microarray analysis from archival plasma samples. Anal Biochem 2013;437:123-5.

21. Ge Q, Zhou Y, Lu J, Bai Y, Xie X, et al. miRNA in plasma exosome is stable under different storage conditions. Molecules 2014;19:1568-75.

22. Grasedieck S, Sorrentino A, Langer C, Buske C, Döhner H, et al. Circulating microRNAs in hematological diseases: principles, challenges, and perspectives. Blood 2013;121:4977-84.

23. Mraz M, Malinova K, Mayer J, Pospisilova S. MicroRNA isolation and stability in stored RNA samples. Biochem Biophys Res Commun 2009;390:1-4.

24. Grasedieck S, Schöler N, Bommer M, Niess JH, Tumani H, et al. Impact of serum storage conditions on microRNA stability. Leukemia 2012;26:2414-6.

25. Lloyd CM. Building better mouse models of asthma. Curr Allergy Asthma Rep 2007;7:231-6.

26. Rosenberg HF, Druey KM. Modeling asthma: pitfalls, promises, and the road ahead. J Leukoc Biol 2018;104:41-8.

27. Brusselle GG, Kips JC, Tavernier JH, van der Heyden JG, Cuvelier CA, et al. Attenuation of allergic airway inflammation in IL-4 deficient mice. Clin Exp Allergy 1994;24:73-80.

28. Johnson JR, Wiley RE, Fattouh R, Swirski FK, Gajewska BU, et al. Continuous exposure to house dust mite elicits chronic airway inflammation and structural remodeling. Am J Respir Crit Care Med 2004;169:378-85.

29. Wynn TA. Type 2 cytokines: mechanisms and therapeutic strategies. Nat Rev Immunol 2015;15:271-82.

30. Halim TY, Krauss RH, Sun AC, Takei F. Lung natural helper cells are a critical source of Th2 cell-type cytokines in protease allergeninduced airway inflammation. Immunity 2012;36:451-63.

31. Moro K, Yamada T, Tanabe M, Takeuchi T, Ikawa T, et al. Innate production of T(H)2 cytokines by adipose tissue-associated c-Kit $(+)$ Sca$1(+)$ lymphoid cells. Nature 2010;463:540-4.

32. Neill DR, Wong SH, Bellosi A, Flynn RJ, Daly M, et al. Nuocytes represent a new innate effector leukocyte that mediates type-2 immunity. Nature 2010;464:1367-70.

33. Monticelli S, Ansel KM, Xiao C, Socci ND, Krichevsky AM, et al. MicroRNA profiling of the murine hematopoietic system. Genome Biol 2005;6:R71.

34. Rossi RL, Rossetti G, Wenandy L, Curti S, Ripamonti A, et al. Distinct microRNA signatures in human lymphocyte subsets and enforcement of the naive state in CD4+ T cells by the microRNA miR-125b. Nat Immunol 2011;12:796-803.

35. Muljo SA, Ansel KM, Kanellopoulou C, Livingston DM, Rao A, et al. Aberrant T cell differentiation in the absence of Dicer. J Exp Med 2005;202:261-9.

36. Cho S, Wu CJ, Yasuda T, Cruz LO, Khan AA, et al. miR-23 27 24 clusters control effector T cell differentiation and function. J Exp Med 2016;213:235-49.

37. Pua HH, Steiner DF, Patel S, Gonzalez JR, Ortiz-Carpena JF, et al. MicroRNAs 24 and 27 suppress allergic inflammation and target a network of regulators of T Helper 2 cell-associated cytokine production. Immunity 2016;44:821-32.

38. Okoye IS, Czieso S, Ktistaki E, Roderick K, Coomes SM, et al. Transcriptomics identified a critical role for Th2 cell-intrinsic miR-155 in mediating allergy and antihelminth immunity. Proc Natl Acad Sci U S A 2014;111:E3081-90.

39. Jiménez-Morales S, Gamboa-Becerra R, Baca V, Del Río-Navarro BE, López-Ley DY, et al. MiR-146a polymorphism is associated with asthma but not with systemic lupus erythematosus and juvenile rheumatoid arthritis in Mexican patients. Tissue Antigens 2012;80:317-21.

40. Polikepahad S, Knight JM, Naghavi AO, Oplt T, Creighton CJ, et al. Proinflammatory role for let-7 microRNAS in experimental asthma. J Biol Chem 2010;285:30139-49.

41. Kumar M, Ahmad T, Sharma A, Mabalirajan U, Kulshreshtha A, et al. Let-7 microRNA-mediated regulation of IL-13 and allergic airway inflammation. J Allergy Clin Immunol 2011;128:1077-85.

42. Vigorito E, Kohlhaas S, Lu D, Leyland R. miR-155: an ancient regulator of the immune system. Immunol Rev 2013;253:146-57.

43. Rodriguez A, Vigorito E, Clare S, Warren MV, Couttet P, et al. Requirement of bic/microRNA-155 for normal immune function. Science 2007;316:608-11.

44. Thai TH, Calado DP, Casola S, Ansel KM, Xiao C, et al. Regulation of the germinal center response by microRNA-155. Science 2007;316:604-8.

45. Johansson K, Malmhäll C, Ramos-Ramírez P, Rådinger M, et al. MicroRNA-155 is a critical regulator of type 2 innate lymphoid cells and IL-33 signaling in experimental models of allergic airway inflammation. J Allergy Clin Immunol 2017;139:1007-16.

46. Malmhäll C, Alawieh S, Lu Y, Sjöstrand M, Bossios A, et al. MicroRNA-155 is essential for T(H)2-mediated allergen-induced eosinophilic inflammation in the lung. J Allergy Clin Immunol 2014;133:1429-38.

47. Lu TX, Hartner J, Lim EJ, Fabry V, Mingler MK, et al. MicroRNA-21 limits in vivo immune response-mediated activation of the IL-12/ IFN-gamma pathway, Th1 polarization, and the severity of delayed-type hypersensitivity. J Immunol 2011;187:3362-73.

48. Divekar R, Kita H. Recent advances in epithelium-derived cytokines (IL-33, IL-25, and thymic stromal lymphopoietin) and allergic inflammation. Curr Opin Allergy Clin Immunol 2015;15:98-103.

49. McKenzie ANJ, Spits H, Eberl G. Innate lymphoid cells in inflammation and immunity. Immunity 2014;41:366-74.

50. Christianson CA, Goplen NP, Zafar I, Irvin C, Good JT Jr, et al. Persistence of asthma requires multiple feedback circuits involving type 2 innate lymphoid cells and IL-33. J Allergy Clin Immunol 2015;136:59-68.

51. Smith SG, Chen R, Kjarsgaard M, Huang C, Oliveria JP, et al. Increased numbers of activated group 2 innate lymphoid cells in the airways 
of patients with severe asthma and persistent airway eosinophilia. J Allergy Clin Immunol 2016;137:75-86.

52. Singh PB, Pua HH, Happ HC, Schneider C, von Moltke J, et al. MicroRNA regulation of type 2 innate lymphoid cell homeostasis and function in allergic inflammation. J Exp Med 2017;214:3627-43.

53. Knolle MD, Chin SB, Rana BMJ, Englezakis A, Nakagawa R, et al. MicroRNA-155 protects group 2 innate lymphoid cells from apoptosis to promote Type-2 immunity. Front Immunol 2018;9:2232.

54. Mattes J, Collison A, Plank M, Phipps S, Foster PS. Antagonism of microRNA-126 suppresses the effector function of TH2 cells and the development of allergic airways disease. Proc Natl Acad Sci U S A 2009;106:18704-9.

55. Collison A, Mattes J, Plank M, Foster PS. Inhibition of house dust mite-induced allergic airways disease by antagonism of microRNA-145 is comparable to glucocorticoid treatment. J Allergy Clin Immunol 2011;128:160-7.

56. Sharma A, Kumar M, Ahmad T, Mabalirajan U, Aich J, et al. Antagonism of mmu-mir-106a attenuates asthma features in allergic murine model. J Appl Physiol (1985) 2012;113:459-64.

57. Li JJ, Tay HL, Maltby S, Xiang Y, Eyers F, et al. MicroRNA-9 regulates steroid-resistant airway hyperresponsiveness by reducing protein phosphatase 2A activity. J Allergy Clin Immunol 2015;136:462-73.

58. Kim RY, Horvat JC, Pinkerton JW, Starkey MR, Essilfie AT, et al. MicroRNA-21 drives severe, steroid-insensitive experimental asthma by amplifying phosphoinositide 3-kinase-mediated suppression of histone deacetylase 2. J Allergy Clin Immunol 2017;139:519-32.

59. Kumar RK, Hitchins MP, Foster PS. Epigenetic changes in childhood asthma. Dis Model Mech 2009;2:549-53.

60. Lü J, Qian J, Chen F, Tang X, Li C, et al. Differential expression of components of the microRNA machinery during mouse organogenesis. Biochem Biophys Res Commun 2005;334:319-23.

61. Dong J, Jiang G, Asmann YW, Tomaszek S, Jen J, et al. MicroRNA networks in mouse lung organogenesis. PLoS One 2010;5:e10854.

62. Williams AE, Moschos SA, Perry MM, Barnes PJ, Lindsay MA. Maternally imprinted microRNAs are differentially expressed during mouse and human lung development. Dev Dyn 2007;236:572-80.

63. Lu Y, Thomson JM, Wong HY, Hammond SM, Hogan BL. Transgenic over-expression of the microRNA miR-17-92 cluster promotes proliferation and inhibits differentiation of lung epithelial progenitor cells. Dev Biol 2007;310:442-53.

64. Bhaskaran M, Wang Y, Zhang H, Weng T, Baviskar P, et al. MicroRNA-127 modulates fetal lung development. Physiol Genomics 2009;37:268-78.

65. Liu F, Qin HB, Xu B, Zhou H, Zhao DY. Profiling of miRNAs in pediatric asthma: upregulation of miRNA-221 and miRNA-485-3p. Mol Med Rep 2012;6:1178-82.

66. Jiang C, Yu H, Sun Q, Zhu W, Xu J, et al. Extracellular microRNA-21 and microRNA-26a increase in body fluids from rats with antigen induced pulmonary inflammation and children with recurrent wheezing. BMC Pulm Med 2016;16:50.

67. Lu TX, Munitz A, Rothenberg ME. MicroRNA-21 is up-regulated in allergic airway inflammation and regulates IL-12p35 expression. J Immunol 2009;182:4994-5002.

68. Sawant DV, Yao W, Wright Z, Sawyers C, Tepper RS, et al. Serum MicroRNA-21 as a biomarker for allergic inflammatory disease in children. Microrna 2015;4:36-40.

69. Hammad Mahmoud Hammad R, Hamed DHED, Eldosoky MAER, Ahmad AAES, Osman HM, et al. Plasma microRNA-21, microRNA146a and IL-13 expression in asthmatic children. Innate Immun 2018;24:171-9.

70. Papadopoulos NG, Arakawa H, Carlsen KH, Custovic A, Gern J, et al. International consensus on (ICON) pediatric asthma. Allergy 2012;67:976-97.

71. Dong X, Xu M, Ren Z, Gu J, Lu M, et al. Regulation of CBL and ESR1 expression by microRNA-223p, 513a-5p and 625-5p may impact the pathogenesis of dust mite-induced pediatric asthma. Int J Mol Med 2016;38:446-56.

72. Midyat L, Gulen F, Karaca E, Ozkinay F, Tanac R, et al. MicroRNA expression profiling in children with different asthma phenotypes. Pediatr Pulmonol 2016;51:582-7.

73. Nakano T, Inoue Y, Shimojo N, Yamaide F, Morita Y, et al. Lower levels of hsa-mir-15a, which decreases VEGFA, in the CD4+ T cells of pediatric patients with asthma. J Allergy Clin Immunol 2013;132:1224-7.

74. Lee CG, Link H, Baluk P, Homer RJ, Chapoval S, et al. Vascular endothelial growth factor (VEGF) induces remodeling and enhances TH2mediated sensitization and inflammation in the lung. Nat Med 2004;10:1095-103.

75. Asai K, Kanazawa H, Kamoi H, Shiraishi S, Hirata K, et al. Increased levels of vascular endothelial growth factor in induced sputum in asthmatic patients. Clin Exp Allergy 2003;33:595-9.

76. Hossny E, El-Awady H, Bakr S, Labib A. Vascular endothelial growth factor overexpression in induced sputum of children with bronchial asthma. Pediatr Allergy Immunol 2009;20:89-96.

77. Davis JS, Sun M, Kho AT, Moore KG, Sylvia JM, et al. Circulating microRNAs and association with methacholine PC20 in the childhood asthma management program (CAMP) cohort. PLoS One 2017;12:e180329.

78. Kho AT, McGeachie MJ, Moore KG, Sylvia JM, Weiss ST, et al. Circulating microRNAs and prediction of asthma exacerbation in childhood asthma. Respir Res 2018;19:128.

79. Kho AT, Sharma S, Davis JS, Spina J, Howard D, et al. Circulating microRNAs: association with lung function in asthma. PLoS One 2016;11:e0157998.

80. Licari A, Castagnoli R, Brambilla I, Marseglia A, Tosca MA, et al. Asthma endotyping and biomarkers in childhood asthma. Pediatr Allergy Immunol Pulmonol 2018;31:44-55.

81. Wenzel SE. Asthma phenotypes: the evolution from clinical to molecular approaches. Nat Med 2012;18:716-25.

82. Pinkerton M, Chinchilli V, Banta E, Craig T, August A, et al. Differential expression of microRNAs in exhaled breath condensates of patients with asthma, patients with chronic obstructive pulmonary disease, and healthy adults. J Allergy Clin Immunol 2013;132:217-9. 
83. Malmhäll C, Johansson K, Winkler C, Alawieh S, Ekerljung L, et al. Altered miR-155 expression in allergic asthmatic airways. Scand J Immunol 2017;85:300-7.

84. Suojalehto H, Lindström I, Majuri ML, Mitts C, Karjalainen J, et al. Altered microRNA expression of nasal mucosa in long-term asthma and allergic rhinitis. Int Arch Allergy Immunol 2014;163:168-78.

85. Fekonja S, Korošec P, Rijavec M, Jeseničnik T, Kunej T. Asthma microRNA regulome development using validated miRNA-target interaction visualization. OMICS 2018;22:607-15.

86. Simpson LJ, Patel S, Bhakta NR, Choy DF, Brightbill HD, et al. A microRNA upregulated in asthma airway T cells promotes TH2 cytokine production. Nat Immunol 2014;15:1162-70.

87. Haj-Salem I, Fakhfakh R, Bérubé JC, Jacques E, Plante S, et al. MicroRNA-19a enhances proliferation of bronchial epithelial cells by targeting TGFbetaR2 gene in severe asthma. Allergy 2015;70:212-9.

88. Sun Q, Liu L, Wang H, Mandal J, Khan P, et al. Constitutive high expression of protein arginine methyltransferase 1 in asthmatic airway smooth muscle cells is caused by reduced microRNA-19a expression and leads to enhanced remodeling. J Allergy Clin Immunol 2017; 140:510-24.

89. Chen L, Xu J, Chu X, Ju C. MicroRNA-98 interferes with thrombospondin 1 expression in peripheral B cells of patients with asthma. Biosci Rep 2017; doi: 10.1042/BSR20170149.

90. Cheng W, Yan K, Xie LY, Chen F, Yu HC, et al. MiR-143-3p controls TGF- $\beta 1$-induced cell proliferation and extracellular matrix production in airway smooth muscle via negative regulation of the nuclear factor of activated T cells 1. Mol Immunol 2016;78:133-9.

91. Huo X, Zhang K, Yi L, Mo Y, Liang Y, et al. Decreased epithelial and plasma miR-181b-5p expression associates with airway eosinophilic inflammation in asthma. Clin Exp Allergy 2016;46:1281-90.

92. Panganiban RP, Wang Y, Howrylak J, Chinchilli VM, Craig TJ, et al. Circulating microRNAs as biomarkers in patients with allergic rhinitis and asthma. J Allergy Clin Immunol 2016;137:1423-32.

93. Panganiban RP, Pinkerton MH, Maru SY, Jefferson SJ, Roff AN, et al. Differential microRNA epression in asthma and the role of miR-1248 in regulation of IL-5. Am J Clin Exp Immunol 2012;1:154-65.

94. Milger K, Götschke J, Krause L, Nathan P, Alessandrini F, et al. Identification of a plasma miRNA biomarker signature for allergic asthma: a translational approach. Allergy 2017;72:1962-71.

95. Levänen B, Bhakta NR, Torregrosa Paredes P, Barbeau R, Hiltbrunner S, et al. Altered microRNA profiles in bronchoalveolar lavage fluid exosomes in asthmatic patients. J Allergy Clin Immunol 2013;131:894-903.

96. Tang X, Wu F, Fan J, Jin Y, Wang J, et al. Posttranscriptional regulation of interleukin-33 expression by microRNA-200 in bronchial asthma. Mol Ther 2018;26:1808-17.

97. Ray A, Kolls JK. Neutrophilic inflammation in asthma and association with disease severity. Trends Immunol 2017;38:942-54.

98. Maes T, Cobos FA, Schleich F, Sorbello V, Henket M, et al. Asthma inflammatory phenotypes show differential microRNA expression in sputum. J Allergy Clin Immunol 2016;137:1433-46.

99. Huang Y, Zhang S, Fang X, Qin L, Fan Y, et al. Plasma miR-199a-5p is increased in neutrophilic phenotype asthma patients and negatively correlated with pulmonary function. PLoS One 2018;13:e0193502.

100. Yuan Y, Ran N, Xiong L, Wang G, Guan X, et al. Obesity-related asthma: immune regulation and potential targeted therapies. J Immunol Res 2018;2018:1943497.

101. Rijavec M, Korošec P, Žavbi M, Kern I, Malovrh MM. Let-7a is differentially expressed in bronchial biopsies of patients with severe asthma. Sci Rep 2014;4:6103.

102. Rupani H, Martinez-Nunez RT, Dennison P, Lau LC, Jayasekera N, et al. Toll-like receptor 7 is reduced in severe asthma and linked to an altered microRNA profile. Am J Respir Crit Care Med 2016;194:26-37.

103. Tsitsiou E, Williams AE, Moschos SA, Patel K, Rossios C, et al. Transcriptome analysis shows activation of circulating CD8+ T cells in patients with severe asthma. J Allergy Clin Immunol 2012;129:95-103.

104. Comer BS, Camoretti-Mercado B, Kogut PC, Halayko AJ, Solway J, et al. MicroRNA-146a and microRNA-146b expression and antiinflammatory function in human airway smooth muscle. Am J Physiol Lung Cell Mol Physiol 2014;307:L727-34.

105. Perry MM, Baker JE, Gibeon DS, Adcock IM, Chung KF. Airway smooth muscle hyperproliferation is regulated by microRNA-221 in severe asthma. Am J Respir Cell Mol Biol 2014;50:7-17.

106. Yin H, Zhang S, Sun Y, Li S, Ning Y, et al. MicroRNA-34/449 targets IGFBP-3 and attenuates airway remodeling by suppressing Nur77mediated autophagy. Cell Death Dis 2017;8:e2998.

107. Solberg OD, Ostrin EJ, Love MI, Peng JC, Bhakta NR, et al . Airway epithelial miRNA expression is altered in asthma. Am J Respir Crit Care Med 2012;186:965-74.

108. Lacedonia D, Palladino GP, Foschino-Barbaro MP, Scioscia G, Carpagnano GE. Expression profiling of miRNA-145 and miRNA-338 in serum and sputum of patients with COPD, asthma, and asthma-COPD overlap syndrome phenotype. Int J Chron Obstruct Pulmon Dis 2017;12:1811-7.

109. Fan L, Wang X, Fan L, Chen Q, Zhang H, et al. MicroRNA-145 influences the balance of Th1/Th2 via regulating RUNX3 in asthma patients. Exp Lung Res 2016;42:417-24.

110. Kärner J, Wawrzyniak M, Tankov S, Runnel T, Aints A, et al. Increased microRNA-323-3p in IL-22/IL-17-producing T cells and asthma: a role in the regulation of the TGF-beta pathway and IL-22 production. Allergy 2017;72:55-65.

111. Jardim MJ, Dailey L, Silbajoris R, Diaz-Sanchez D. Distinct microRNA expression in human airway cells of asthmatic donors identifies a novel asthma-associated gene. Am J Respir Cell Mol Biol 2012;47:536-42.

112. Chen X, Ba Y, Ma L, Cai X, Yin Y, et al. Characterization of microRNAs in serum: a novel class of biomarkers for diagnosis of cancer and other diseases. Cell Res 2008;18:997-1006. 
113. Mitchell PS, Parkin RK, Kroh EM, Fritz BR, Wyman SK, et al. Circulating microRNAs as stable blood-based markers for cancer detection. Proc Natl Acad Sci U S A 2008;105:10513-8.

114. Zen K, Zhang CY. Circulating microRNAs: a novel class of biomarkers to diagnose and monitor human cancers. Med Res Rev 2012;32:326-48.

115. Bouchie A. First microRNA mimic enters clinic. Nat Biotechnol 2013;31:577.

116. Ørum H. Locked nucleic acids as microRNA therapeutics. In: Lawrie CH, editor. MicroRNAs in medicine. John Wiley \& Sons: Inc; 2013. pp. 663-72.

117. Rai K, Takigawa N, Ito S, Kashihara H, Ichihara E, et al. Liposomal delivery of MicroRNA-7-expressing plasmid overcomes epidermal growth factor receptor tyrosine kinase inhibitor-resistance in lung cancer cells. Mol Cancer Ther 2011;10:1720-7.

118. Trang P, Wiggins JF, Daige CL, Cho C, Omotola M, et al. Systemic delivery of tumor suppressor microRNA mimics using a neutral lipid emulsion inhibits lung tumors in mice. Mol Ther 2011;19:1116-22.

119. van Zandwijk N, Pavlakis N, Kao SC, Linton A, Boyer MJ, et al. Safety and activity of microRNA-loaded minicells in patients with recurrent malignant pleural mesothelioma: a first-in-man, phase 1, open-label, dose-escalation study. Lancet Oncol 2017;18:1386-96.

120. Vlachos IS, Zagganas K, Paraskevopoulou MD, Georgakilas G, Karagkouni D, et al. DIANA-miRPath v3.0: deciphering microRNA function with experimental support. Nucleic Acids Res 2015;43:W460-6.

121. Chou CH, Chang NW, Shrestha S, Hsu SD, Lin YL, et al. miRTarBase 2016: updates to the experimentally validated miRNA-target interactions database. Nucleic Acids Res 2016;44:D239-47.

122. Chou CH, Shrestha S, Yang CD, Chang NW, Lin YL, et al. miRTarBase update 2018: a resource for experimentally validated microRNAtarget interactions. Nucleic Acids Res 2018;46:D296-302.

123. Lee YJ, Kim V, Muth DC, Witwer KW. Validated microRNA target databases: an evaluation. Drug Dev Res 2015;76:389-96. 